\title{
Five-year results of a clinical pilot study utilizing a pedicle-lengthening osteotomy for the treatment of lumbar spinal stenosis
}

\author{
Sergey Mlyavykh, MD, PhD, ${ }^{1}$ Steven C. Ludwig, MD, ${ }^{2}$ Christopher K. Kepler, MD, MBA, ${ }^{3}$ and \\ D. Greg Anderson, MD ${ }^{3}$ \\ ${ }^{1}$ Privolzhski Federal Medical Research Center, Nizhniy Novgorod, Russia; ${ }^{2}$ Department of Orthopaedics, University of Maryland \\ School of Medicine, Baltimore, Maryland; and ${ }^{3}$ Department of Orthopaedics, Thomas Jefferson University/Rothman Institute, \\ Philadelphia, Pennsylvania
}

OBJECTIVE Lumbar spinal stenosis (LSS) is a common condition that leads to significant disability, particularly in the elderly. Current therapeutic options have certain drawbacks. This study evaluates the 5-year clinical and radiographic results of a minimally invasive pedicle-lengthening osteotomy (PLO) for symptomatic LSS.

METHODS A prospective, single-arm, clinical pilot study was conducted involving 20 patients (mean age 61.7 years) with symptomatic LSS treated by a PLO procedure at 1 or 2 lumbar levels. All patients had symptoms of neurogenic claudication or radiculopathy secondary to LSS, and had not improved after a minimum 6-month course of nonoperative treatment. Eleven patients had a Meyerding grade I degenerative spondylolisthesis in addition to LSS. Clinical outcomes were measured using the Oswestry Disability Index, Zürich Claudication Questionnaire, 12-Item Short Form Health Survey, and a visual analog scale for back and leg pain. Procedural variables, neurological outcomes, adverse events, and radiological imaging (plain radiographs and CT scans) were collected at the 1.5-, 3-, 6-, 9-, 12-, 24-, and 60-month time points.

RESULTS The PLOs were performed through percutaneous incisions, with minimal blood loss in all cases. There were no operative complications. Four adverse events occurred during the follow-up period. Statistically significant improvement was observed in each of the outcome instruments and maintained over the 5-year follow-up period. Imaging studies, reviewed by an independent radiologist, showed no evidence of device subsidence, migration, breakage, or heterotopic ossification. Thin-slice CT scans documented healing of the osteotomy site in all patients at the 6-month time point and an increase of $115 \%$ in the mean cross-sectional area of the spinal canal.

CONCLUSIONS Treatment of patients with symptomatic LSS with a PLO procedure provided substantial enlargement of the area of the spinal canal and favorable clinical results for both disease-specific and non-disease-specific outcome measures at all follow-up time points out to 5 years. Future research is needed to compare this technique to alternative therapies for LSS.

https://thejns.org/doi/abs/10.3171/2017.11.SPINE16664

KEYWORDS lumbar; spine; spinal stenosis; decompression; pedicle osteotomy; minimally invasive; clinical trial; spondylolisthesis

$\mathrm{L}$ UMBAR spinal stenosis (LSS) is defined as a reduction in the diameter of the spinal canal and/or neural foramina. ${ }^{3}$ The most frequent cause of LSS is degenerative changes, including narrowing and bulging of the intervertebral disc, hypertrophy of the facet joints, thickening and buckling of the ligamentum flavum, and/ or degenerative spondylolisthesis. Lumbar spinal stenosis most commonly affects the L4-5 segment, but can affect any lumbar level. ${ }^{1}$ Affected patients often suffer from symptoms of back and/or leg pain, which limits their ability to stand and ambulate.

Unfortunately, nonsurgical therapies for LSS may be

ABBREVIATIONS ASA = American Society of Anesthesiologists; ICC = intraclass correlation coefficient; LSS = lumbar spinal stenosis; ODI = Oswestry Disability Index; PLO = pedicle-lengthening osteotomy; SF-12 = 12-Item Short Form Health Survey; SPORT = Spine Patient Outcomes Research Trial; VAS = visual analog scale; ZCQ = Zürich Claudication Questionnaire.

SUBMITTED June 14, 2016. ACCEPTED November 16, 2017

INCLUDE WHEN CITING Published online June 1, 2018; DOI: 10.3171/2017.11.SPINE16664. 
ineffective for some patients, especially those with more severe stenosis, advanced age, or medical comorbidities. ${ }^{2}$ Surgical decompression, with or without lumbar fusion, has been shown to produce better clinical improvement compared with nonoperative treatment for severely affected patients. ${ }^{37}$ Traditional open decompressive lumbar surgery, although effective in relieving compression of the neural elements, has certain drawbacks, including the risks of significant blood loss, wound infection, iatrogenic instability, perineural scarring, medical complications, and prolonged recovery. ${ }^{11}$ In addition, the pain relief achieved through open decompressive surgery may degrade over time, requiring further, more complex revision surgery. ${ }^{16}$

The pedicle-lengthening osteotomy (PLO) procedure is a relatively new treatment for LSS. This procedure involves enlargement of the spinal canal and neural foramen through an expanding osteotomy at the base of the lumbar pedicles. This procedure is performed percutaneously, using fluoroscopic guidance, and is analogous to other wellknown percutaneous pedicle-targeting procedures such as vertebroplasty.

In a prior issue of the Journal of Neurosurgery: Spine, the 1-year results of a pilot study investigating the PLO were reported. ${ }^{22}$ This study found statistically significant improvements in pain, physical function, and low-back disability following the PLO procedure. This current study reports the 5-year clinical and radiological results in the pilot cohort.

\section{Methods}

Twenty patients with symptomatic LSS were enrolled in a prospective, single-treatment clinical trial following institutional ethics board approval. Patient selection was conducted at an academic center by offering participation in the trial to all patients who presented with symptomatic spinal stenosis, with or without a grade I spondylolisthesis, and who were deemed candidates for surgery. The first 20 patients who met all study inclusion and exclusion criteria and who were interested in participating in the trial were enrolled. Nineteen patients were available for follow-up at the 2-year and 18 patients were available for follow-up at the 5-year postoperative time points. The inclusion and exclusion criteria for the study are shown in Table 1.

\section{Outcome Assessment}

Validated, patient-based outcome instruments were used to assess the clinical results in the patient cohort. These included the Oswestry Disability Index (ODI) (version 2.0), ${ }^{24}$ Zürich Claudication Questionnaire (ZCQ), ${ }^{28,29}$ $100-\mathrm{mm}$ visual analog scale (VAS) for pain, and 12-Item Short Form Health Survey (SF-12), version 2. The assessed time points included baseline (within 2 weeks prior to the procedure) and postoperatively at $1.5-, 3-, 6-, 9-$, 12-, 24-, and 60-month time points. At each time point, patients completed a clinical questionnaire, provided information on medication usage, and underwent a physical and neurological examination to ascertain any evidence of an adverse event. Additionally, anteroposterior and lateral radiographs were obtained at baseline and at the 1.5-, 3-, 6-, 9-, and 12-month postoperative time points. A thinslice CT scan of the lumbar spine was obtained at baseline and at the 6-month postoperative time point. Lumbar MRI was performed at baseline.

\section{Surgical Technique}

Patients were treated either with local anesthesia and conscious sedation $(\mathrm{n}=1)$ or with general anesthesia ( $\mathrm{n}$ =19). Patients were positioned prone on a radiolucent operating table with a standard sterile field encompassing the lumbar spine. A C-arm fluoroscopy unit (model 9800; General Electric) was used to image the vertebral levels undergoing operation. The PLO procedures were performed bilaterally at the levels affected by symptomatic stenosis. Patients with isolated lateral recess stenosis underwent lengthening of the pedicles immediately caudal to the stenotic disc space. Patients with central stenosis underwent lengthening of the pedicles immediately above and below the stenotic disc space.

TABLE 1. Study inclusion and exclusion criteria

\begin{tabular}{|c|c|}
\hline Inclusion Criteria & Exclusion Criteria \\
\hline Male or female btwn $40 \& 80 \mathrm{yrs}$ of age & Patient has a history of previous surgery to the lumbar spine \\
\hline $\begin{array}{l}\text { Patient has disabling pain in the buttock \&/or thighs \&/or calves, defined as } \\
\text { neurogenic claudication or radiculopathy due to LSS }\end{array}$ & Patient has $\geq$ grade II spondylolisthesis \\
\hline $\begin{array}{l}\text { MRI or CT w/ myelography demonstrate narrowing of the central canal, lat- } \\
\text { eral recess, \&/or neural foramen that correlates } w / \text { the patient's symptoms }\end{array}$ & Patient has $>15^{\circ}$ of lumbar scoliosis \\
\hline $\begin{array}{l}\text { Patient has undergone a minimum of } 6 \text { mos of nonop treatment, including } \\
\geq 1 \text { of the following: NSAIDs, epidural injections, physical therapy, or pain } \\
\text { management w/ medications }\end{array}$ & $\begin{array}{l}\text { Patient requires treatment during or after surgery w/ a drug that } \\
\text { interferes w/ bone metabolism (NSAIDs, corticosteroids, bisphos- } \\
\text { phonates, chemotherapy for cancer, immunosuppressive agents), or } \\
\text { patient requires radiation }\end{array}$ \\
\hline \multirow{2}{*}{$\begin{array}{l}\text { Primary investigator believes the patient is a candidate for lumbar decom- } \\
\text { pression to address the symptoms }\end{array}$} & Patient smokes or uses tobacco products \& is unwilling to quit \\
\hline & $\begin{array}{l}\text { Patient has a documented history or radiographic evidence of a meta- } \\
\text { bolic bone disease (such as osteoporosis) or another condition (such } \\
\text { as a history of Paget disease, osteomalacia, or another osteodystro- } \\
\text { phy) that would negatively impact the bone healing process }\end{array}$ \\
\hline
\end{tabular}


Using the en face fluoroscopic view, the position of the pedicles was marked out bilaterally on the skin (Fig. 1). Ten-millimeter skin incisions were made bilaterally in line with the central axis of the pedicles to be lengthened. Next, a $2.7-\mathrm{mm}$ guide pin was driven through the central axis of each pedicle into the vertebral body (Fig. 2A-C). Care was taken to ensure that the pins passed within $2 \mathrm{~mm}$ of the center of each pedicle on both en face and lateral fluoroscopic views. A cannulated pedicle reamer (Innovative Surgical Designs) was then introduced over the guide pin and a passage was reamed through each pedicle, into the vertebral body (Fig. 2D).

Next, pedicle osteotomies were performed bilaterally by using a manual bone saw (Innovative Surgical Designs; Fig. 3A and B). The manual bone saw was designed to cut the pedicles from inside the pedicle passages. The cutting process was monitored by the surgeon, using a combination of tactile feedback and fluoroscopic control (Fig. 3C and $\mathrm{D})$. The manual bone saw had a side-cutting blade that could be extended and retracted by the surgeon. Each pedicle was cut in sections to ensure that the saw blade did not extend beyond the outer cortex of the pedicle. Using gentle rotation of the bone saw, the surgeon was able to shave away a thin $(0.5-\mathrm{mm})$ channel of bone at the junction of the pedicle and vertebral body until the outer cortex of the pedicle was breeched. The saw blade was then retracted and the saw was adjusted to cut a different section of the pedicle, repeating the cutting process. When the entire pedicle circumference was cut, the saw blade was retracted and the bone saw was removed.

After the pedicles were cut, a specialized bone screw (Altum; Innovative Surgical Designs) (Fig. 4A and B) was threaded into each of the pedicle passages (Fig. 4C and D). The bone screws were positioned precisely at the osteotomy sites and then simultaneously lengthened by 4.8 $\mathrm{mm}$, using an internal threaded mechanism. Bone screw lengthening created a gap at the site of the osteotomy, pushing the anterior elements (vertebral body) away from the posterior elements (pedicle, facets, lamina). This maneuver enlarged the area of the spinal canal and neural foramen. Fluoroscopic imaging was used to confirm proper positioning of the bone screw implants, and then a locking mechanism was applied to secure the construct. The skin
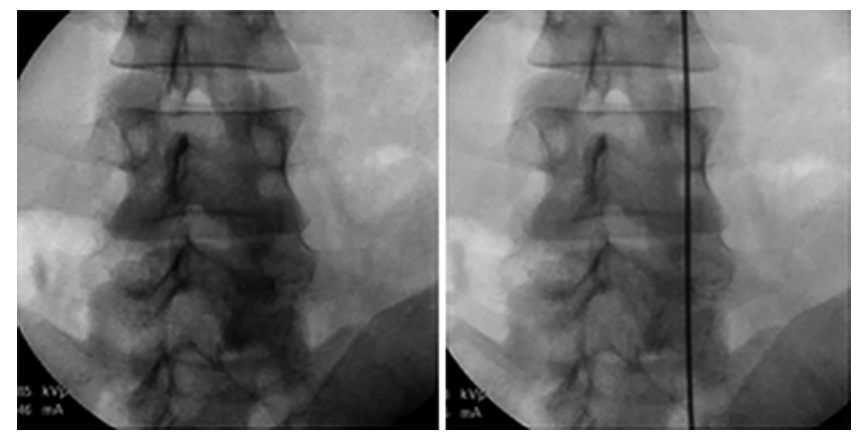

FIG. 1. The en face fluoroscopic view is used to target the pedicle. Using the en face view, a K-wire is centered over the pedicle with vertical (shown) and horizontal alignment to the image. The point where the horizontal and vertical lines intersect is marked on the skin, and this is the correct location of the incision that will be used to access the pedicle.

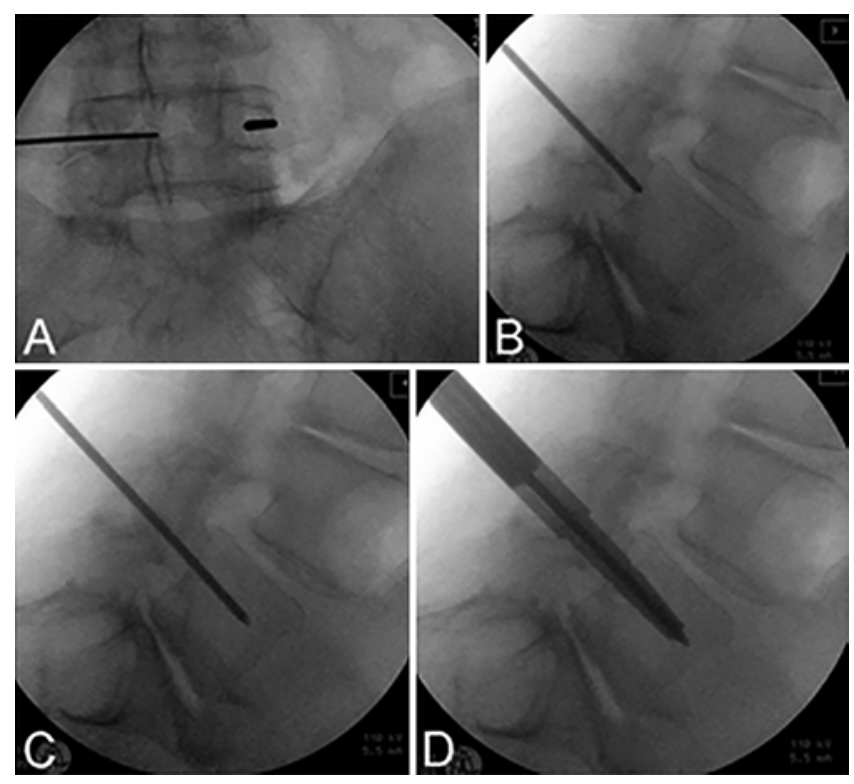

FIG. 2. A and B: The right pedicle is targeted with a guide pin that is centered within $2 \mathrm{~mm}$ of the center of the pedicle. $\mathrm{C}$ : The guide pin is then driven through the pedicle into the vertebral body. D: A cannulated reamer is placed over the guide wire and used to open a passage through the pedicle.
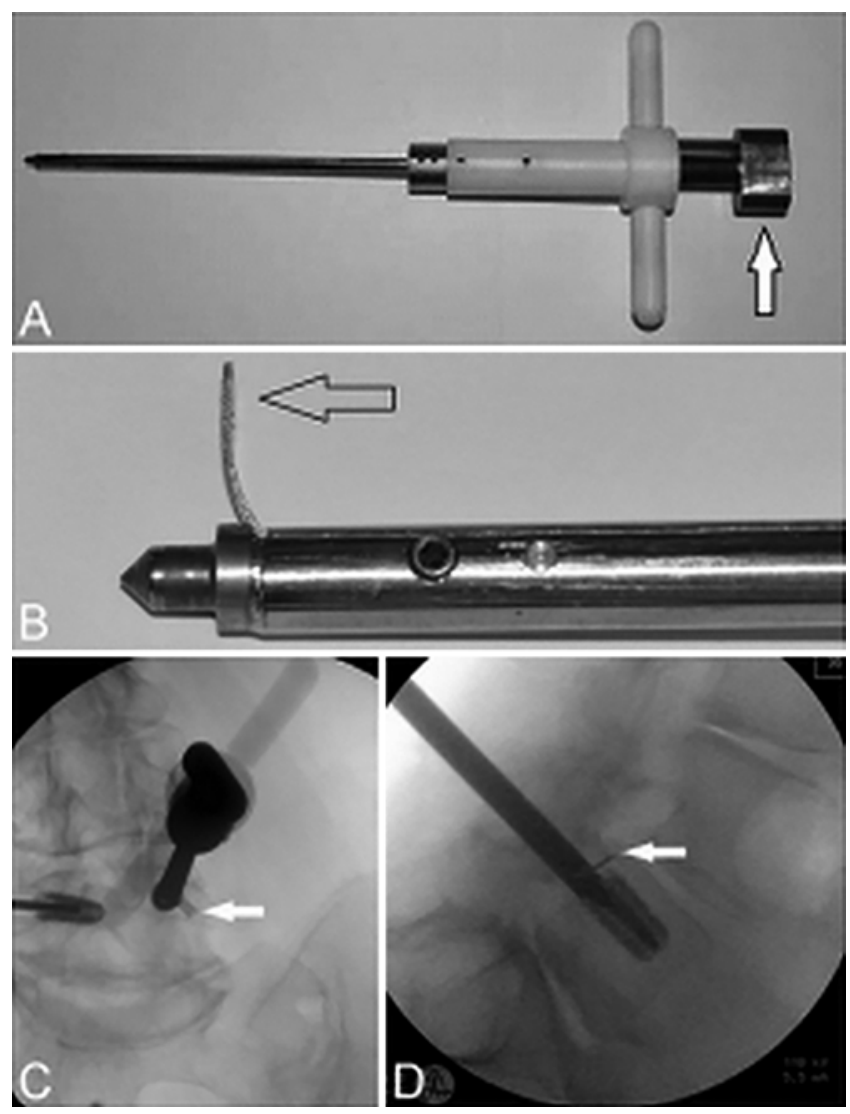

FIG. 3. A: The pedicle saw is a hand instrument that is used to cut the pedicle. The white arrow points to an adjustment knob used to extend and retract the saw blade. B: The thin, semiflexible blade (arrows) exits the side of the saw near its tip. C and D: The position of the saw blade is followed on the en face and lateral fluoroscopic images during pedicle cutting. 

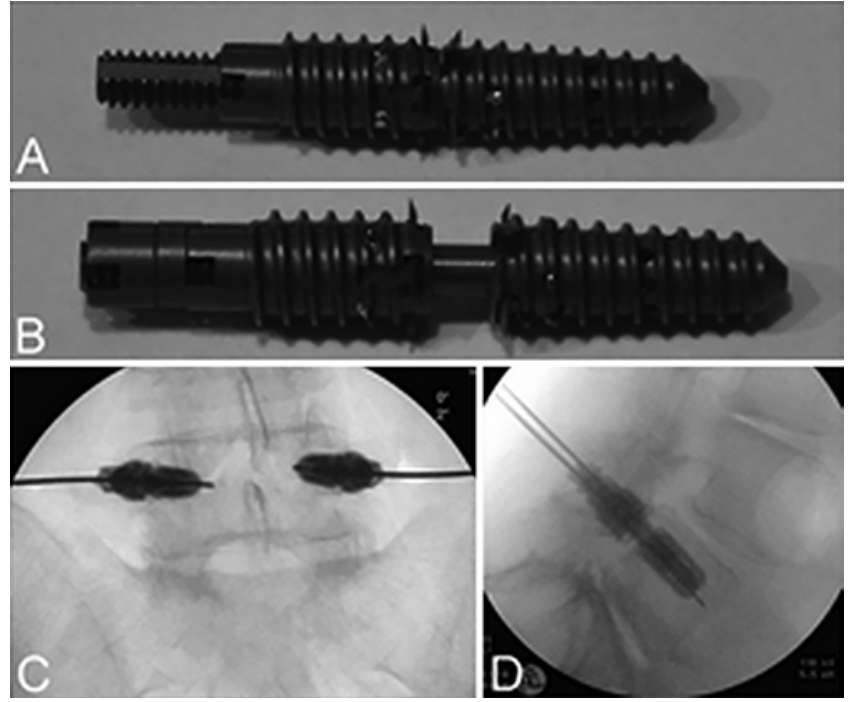

FIG. 4. A: The pedicle-lengthening implant is a bone screw that is threaded into the pedicle passage. B: A central, threaded mechanism is used to lengthen the screw after it is positioned within the pedicle passage. C and D: Anteroposterior and lateral views of the pediclelengthening implant after lengthening has been performed and prior to removal of the guide wires.

incisions were sutured and local anesthetic (bupivacaine; Hospira) was injected subcutaneously around the incisions to reduce postoperative pain.

Following the procedure, patients were encouraged to ambulate as soon as they had recovered from anesthesia. Patients were instructed to avoid bending or twisting at the waist for 6 weeks following the procedure to allow healing across the osteotomy sites. No bracing was used.

\section{Morphometric Measurements}

The preoperative and 6-month postoperative CT scans were used to determine the cross-sectional area of the spinal canal before and after the PLO procedure. Axial images in line with the mid-disc space of the stenotic level were selected and imported into a digital image analysis package (Digital Earthwatch Software, http://www. lawrencehallofscience.org/gss/rev/ip/).

Two experienced spine surgeons manually calibrated each image, using the width of the vertebral body as a standard reference length. Using the polygon tool for area measurement, the spinal canal of each image was traced, placing between 15 and 20 points along the margins of the spinal canal to form an enclosed polygon. The area inside each polygon was calculated by the software in pixels. The cross-sectional areas of the spinal canals at the preoperative and 6-month postoperative time points were compared using the following formula: \% change in spinal canal area $=[($ Final area - Original area $) /$ Original area $]$ $\times 100$.

\section{Statistical Analysis}

Preoperative and postoperative scores for each of the patient-based outcome instruments were compared using a paired Student t-test in the SPSS statistical software pro-
TABLE 2. Patient variables in a pilot cohort treated for LSS

\begin{tabular}{lc}
\hline \multicolumn{1}{c}{ Variable } & Value \\
\hline No. of patients & 20 \\
\hline Age (yrs) & 61.7 \\
\hline Mean & $47-77$ \\
\hline Range & 8 \\
\hline Sex & 12 \\
\hline Male & \\
\hline Female & 11 \\
\hline Body mass index & 9 \\
\hline $25-29.9$ & 8 \\
\hline$\geq 30$ & 11 \\
\hline ASA physical status classification & 1 \\
\hline Class II & \\
\hline Class III & 9 \\
\hline Class IV & 11 \\
\hline Presence of spondylolisthesis &
\end{tabular}

gram (version 18.0; SPSS, Inc.). Significance was defined as $p<0.05$. A comparison of relative spinal canal measurements was assessed using the intraclass correlation coefficient (ICC). The ICC was defined as excellent for a value of $0.90-1.0$, good for a value of $0.70-0.89$, fair for a value of $0.50-0.69$, and poor for a value $\leq 0.49{ }^{8}$

\section{Results}

Patient variables are shown in Table 2. The study included 12 females and 8 males. The mean age of the patients at the time of surgery was 61.7 years (range 47-77 years). All patients had symptomatic LSS and had not improved after at least 6 months of nonoperative treatment with lumbar epidural steroid injections, NSAIDs, analgesic drugs, and physical therapy. Eleven patients had a Meyerding grade I degenerative spondylolisthesis and 9 had no spondylolisthesis. All patients had one or more medical comorbidities. The American Society of Anesthesiologists (ASA) Physical Status Classification for the patients was ASA class II in 8 patients, ASA class III in 11 patients, and ASA class IV in 1 patient. The body mass index of the patients was between 25 and 29.9 in 11 patients and $\geq 30$ in 9 patients.

\section{Operative Results}

The specific pedicles lengthened in this study are shown in Table 3. Overall, there were 10 patients treated with a 1-level bilateral procedure and 10 treated with 2-level bilateral procedures. The most common level treated was L-5 (19 patients), followed by L-4 (9 patients) and L-3 (2 patients). The most common combination of levels was L-4 and L-5 (8 patients). The mean procedure time for a 1-level procedure ( 2 pedicles) was 63 minutes, whereas the mean time for a 2 -level procedure (4 pedicles) was 118 minutes. The mean time for fluoroscopic usage 
TABLE 3. Treated levels in patients with LSS

\begin{tabular}{cc}
\hline \multicolumn{1}{c}{ Level } & No. \\
\hline No. of levels treated & 10 \\
\hline 1 & 10 \\
\hline 2 & 2 \\
\hline Levels treated (bilat lengthening) & 9 \\
\hline L-3 & 19 \\
\hline L-4 & \\
\hline L-5 & 10 \\
\hline Combinations of levels treated & 8 \\
\hline L-5 only & 1 \\
\hline L-4 \& L-5 & 1 \\
\hline L-3 \& L-5 & \\
\hline L-3 \& L-4 & 38 \\
\hline Pedicles lengthened & 18 \\
\hline L-5 & 4 \\
\hline L-4
\end{tabular}

for a 1- and 2-level procedure was 2 minutes, 15 seconds, and 3 minutes, 34 seconds, respectively. The blood loss in all cases was minimal and involved 2-5 lightly bloodied 4 $\times 4$-inch sponges used to clean the incisional areas during the procedure. No suction was used during the surgical procedures.

\section{Adverse Events}

No intraoperative complications were encountered during the study. No patients required conversion to an open procedure. There were no apparent dural lacerations, no apparent nerve root injuries, and no new neurological deficits encountered during the study. Four postoperative adverse events were encountered. The first event involved a patient who reported severe low-back muscle spasms on the evening of the procedure and was treated with a muscle relaxant (cyclobenzaprine; Ortho-McNeil-Jassen). The muscle spasms resolved within 24 hours and required no further treatment. Three other patients reported an incomplete response to treatment, with either residual $(n=1)$ or recurrent $(n=2)$ pain symptoms in their buttocks or legs that were believed by the primary investigator (S.M.) to be possibly related to residual lumbar stenosis. These 3 pa- tients were returned to the operating room between 6 and 18 months after the index procedure for an open lumbar laminectomy. A posterolateral fusion was also performed in 2 of these patients with coexistent degenerative spondylolisthesis. At the time of open surgery, healing of the pedicle osteotomies was confirmed and the bone screws were found to be intact without breakage, migration, or neural impingement. One bone screw in 1 patient was found to be loose. This patient had the most severe medical comorbidities in the study (ASA class IV) and had LSS without spondylolisthesis. She had undergone a 2-level procedure at the L-4 and L-5 pedicles. On further workup, she was found to have severe osteoporosis, an exclusionary criterion for the study, which probably contributed to the bone screw loosening.

\section{Outcome Assessment}

The clinical response to treatment is summarized in Table 4. Clinically significant improvement was observed in the mean outcome scores for each of the validated outcome instruments at each of the postoperative time points, out to the 5-year follow-up period. Comparing the preoperative, 1- to 2-year, and 5-year values, the mean ODI scores improved from a baseline of 52.26 to 28.06 (change of 24.2, $\mathrm{p}=0.00005$ ) at the 1 -year time point; to 22.6 (change of 29.66, $\mathrm{p}<0.0001$ ) at the 2 -year time point; and to 18.7 (change of $33.56 \mathrm{p}<0.0001$ ) at the 5-year time point. The ZCQ physical function domain improved from a baseline of 2.7 to 1.84 (change of $0.86, p=0.002$ ) at the 1-year time point; to 1.6 (change of $1.1, \mathrm{p}<0.0001$ ) at the 2-year time point; and to 1.5 (change of 1.2, $\mathrm{p}=0.0002$ ) at the 5-year time point. The ZCQ symptom severity domain improved from a baseline of 3.16 to 2.18 (change of $0.98, \mathrm{p}<0.00003$ ) at the 1 -year time point; to 1.8 (change of $1.36, \mathrm{p}<0.0001$ ) at the 2 -year time point; and to 1.9 (change of $1.26, \mathrm{p}<0.0001$ ) at the 5 -year time point. The SF-12 physical component scale improved from a baseline of 29.96 to $37.85(\mathrm{p}=0.002)$ at the 1 -year time point; to $38.6(\mathrm{p}=0.0007)$ at the 2-year time point; and to $38.3(\mathrm{p}$ $=0.01)$ at the 5-year time point. The SF-12 mental component scale improved from a baseline of 34.84 to 45.99 ( $\mathrm{p}=$ $0.001)$ at the 1 -year time point; to $50.3(\mathrm{p}=0.0004)$ at the 2-year time point; and to $53.0(\mathrm{p}<0.0001)$ at the 5-year time point. The VAS score for leg pain while standing improved from a baseline of 7.17 to 2.68 ( $p<0.0000066)$ at the 1 -year time point; to $1.5(\mathrm{p}<0.0001)$ at the 2 -year time point; and to $1.9(\mathrm{p}<0.0001)$ at the 5 -year time point. The

TABLE 4. Patient-based outcome measure results

\begin{tabular}{lcccc}
\hline \multicolumn{1}{c}{ Index } & Baseline & 1 Yr & 2 Yrs & 5 Yrs \\
\hline ODI & 52.26 & $28.06, p=0.000052$ & $22.6, p<0.0001$ & $18.7, p<0.0001$ \\
\hline ZCQ physical function domain & 2.71 & $1.84, p=0.002$ & $1.6, p<0.0001$ & $1.5, p=0.0002$ \\
\hline ZCQ symptom severity domain & 3.16 & $2.18, p=0.00003$ & $1.8, p<0.0001$ & $1.9, p<0.0001$ \\
\hline SF-12 physical component score & 29.96 & $37.85, p=0.0024$ & $38.6, p=0.0007$ & $38.3, p=0.01$ \\
\hline SF-12 mental component score & 34.84 & $45.99, p=0.0013$ & $50.3, p=0.0004$ & $53.0, p<0.0001$ \\
\hline VAS (worst low-back pain) & 5.05 & $2.4, p<0.0029$ & $2.4, p=0.001$ & $2.7, p=0.01$ \\
\hline VAS (leg pain standing) & 7.17 & $2.68, p<0.0000066$ & $1.5, p<0.0001$ & $1.9, p<0.0001$ \\
\hline
\end{tabular}


VAS score for worst low-back pain improved from a baseline of 5.05 to $2.4(\mathrm{p}<0.0029)$ at the 1 -year time point; to $2.4(\mathrm{p}=0.001)$ at the 2-year time point; and to $2.7(\mathrm{p}=$ $0.01)$ at the 5 -year time point.

\section{Radiological Studies}

All imaging studies were reviewed by an independent radiologist. Plain anteroposterior and lateral radiographs obtained at the 1.5-, 3-, 6-, 9-, and 12-month time points were evaluated for evidence of device subsidence, loosening, migration, and breakage. No evidence of device subsidence, migration, or breakage was found. One patient had evidence of unilateral device loosening, with a 2-mm "halo" observed along the borders of the implant on imaging (see Adverse Events for additional details of this case).

A thin-slice spiral CT study with reconstructed sagittal and coronal images was performed at the 6-month postoperative time point and was evaluated for bridging bone at the osteotomy sites and for the presence of heterotopic ossification within the spinal canal or neural foramen. All 20 patients demonstrated bridging bone at their osteotomy sites on the 6-month postoperative $\mathrm{CT}$ scans, consistent with healing of the osteotomies (Fig. 5). No patients showed evidence of heterotopic bone formation within the spinal canal or neural foramen on the 6-month CT studies.

\section{Morphometric Data}

The change in the cross-sectional area of each patient's spinal canal was measured and compared between baseline and the 6-month postoperative CT scan. The ICC for the measurement technique was found to be 0.88 , which was defined as good agreement between the reviewers. All patients demonstrated an increase in the mean crosssectional area of the spinal canals on the 6-month CT scan as compared with the preoperative CT scan. The mean increase in spinal canal area was found to be $115 \%$, meaning that this technique more than doubled the cross-sectional area of the spinal canal.

\section{Lost to Follow-Up}

One patient died of an unrelated cause 18 months after the index surgical procedure. At the 2-year follow-up time point, 19 patients provided clinical follow-up data. At the 5-year follow-up time point, 1 additional patient was unable to be located and 18 patients provided clinical followup data.

\section{Discussion}

Although radiological studies commonly demonstrate narrowing of the spinal canal in elderly individuals $(>62$ years old), only a subset develop significant LSS symptoms. ${ }^{1,3}$ Unfortunately, some affected individuals with LSS develop severe and progressive neurogenic symptoms that may lead to a loss of functional independence. Several nonoperative and operative treatments have been suggested to be beneficial for patients with LSS. ${ }^{33}$ The Spine Patient Outcomes Research Trial (SPORT) found nonoperative treatments to be inferior to surgical decompression at a minimum 4-year time point for symptomatic patients. ${ }^{35,36}$ Traditional surgical decompression for LSS involves re-
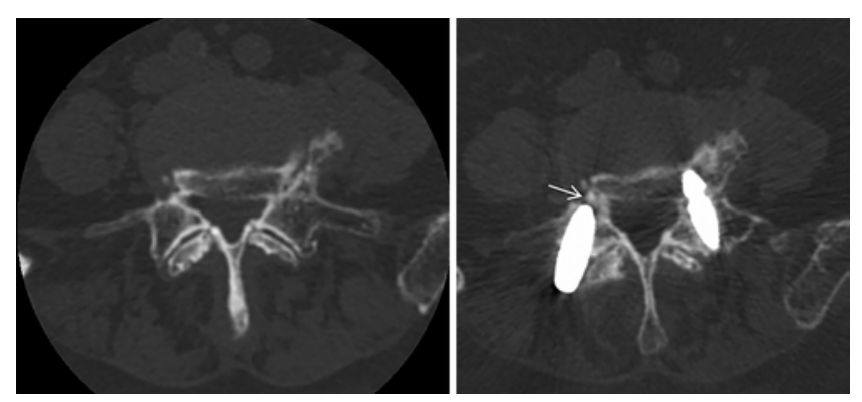

FIG. 5. Before (left) and after (right) axial CT scans of the L-5 level. Note the increased length of the pedicles and the increased size of the spinal canal following the PLO procedure. In addition, notice bridging bone (arrow) at the site of the osteotomy on this 6-month postoperative CT scan.

moval of portions of the spinal lamina, ligamentum flavum, and medial facet joint to alleviate compression of the neural elements. When LSS is associated with radiological evidence of spondylolisthesis or significant scoliosis, a spinal fusion may be included to prevent progression of the spinal deformity. ${ }^{32}$ The rate of surgery for LSS varies widely in different geographic regions but is increasing worldwide. Jansson and colleagues reported a rate of LSS surgery of 13.2 per 100,000 Swedish citizens in 1999 , and noted a 3-fold increase between 1987 and 1999.14 In the US, the rates of surgery for LSS varied from 30 to 132 operations per 100,000 Medicare enrollees across different regions. ${ }^{10}$

The results of traditional lumbar decompression can be assessed in various ways. Turner et al. performed a metaanalysis of 74 studies and found the mean rate of good to excellent results to be $64 \%{ }^{34}$ Weinstein et al. found significant improvements in quality of life and pain measures for patients treated with open lumbar decompression compared with those treated nonsurgically at all time points out to 4 years following surgery. ${ }^{36}$ Using Medicare claims, Deyo et al. reported life-threatening complications in $2.3 \%-5.6 \%$ of patients undergoing surgery for LSS, depending on the invasiveness of the surgical approach. ${ }^{9}$ Additionally, they found that $7.8 \%-13 \%$ of patients required hospital readmission within the first 30 days following surgery. Reoperation for LSS has been reported to range from $11 \%$ within 10 years of surgery in a Swedish study ${ }^{15}$ to $23 \%$ within $8-10$ years in the prospective, observational Maine cohort study. ${ }^{5}$ Toyone et al. reported that $29 \%$ of patients treated with traditional lumbar decompression for LSS were not satisfied at follow-up. ${ }^{31}$ Katz et al. found less satisfactory outcomes following lumbar decompression in patients with self-reported health status that was less than good or excellent, and in those with cardiovascular comorbidities, which are unfortunately common in the elderly population. ${ }^{16}$ In a 7 - to 10 -year follow-up study, Katz et al. reported that $33 \%$ of patients complained of severe back pain and 23\% required additional surgery following open lumbar decompression. ${ }^{17}$ Clearly, there is room for improvement in the treatment of LSS.

Minimally invasive techniques for lumbar decompression have become increasingly popular in recent years. These procedures often use a tubular retractor system 
or spinal endoscope that limits soft-tissue damage from the surgical approach.,39 Minimally invasive surgical approaches for LSS are available, with the purported advantages of less muscle damage, blood loss, hospitalization, and recovery time. ${ }^{13,26}$ One small study found that minimally invasive techniques could be successfully used in an elderly population, with a relatively low rate of serious complications. ${ }^{23} \mathrm{Fu}$ et al. reported fewer deaths and neurological complications in patients treated with minimally invasive techniques compared with those undergoing open surgery for lumbar stenosis. ${ }^{12}$ Despite these reports, minimally invasive lumbar decompression has not yet become the gold standard approach for LSS, perhaps due to the documented concerns regarding the steep learning curve for minimally invasive surgery and/or the perceived risk of a technical complication. ${ }^{21}$ High-quality studies comparing the outcomes of open laminectomy to minimally invasive decompression for LSS are currently lacking. ${ }^{12,25}$

Interspinous spacers have been promoted as a less invasive option for degenerative lumbar stenosis, and may be useful for the subset of patients with good symptom relief when sitting. ${ }^{41}$ In the US, the X-Stop device (Medtronic Spine) was approved by the FDA in 2005 for the treatment of LSS. Interspinous spacers, such as the X-Stop device, maintain the integrity of the spinal canal and may have less approach-related morbidity compared with open lumbar decompression. In a multicenter, prospective trial, the $\mathrm{X}$-Stop device was found to be superior to nonoperative treatment for LSS. ${ }^{40}$ Unfortunately, the published studies on interspinous spacers demonstrate variable success rates, with some studies reporting high rates of failure and/ or revision surgery. ${ }^{6,7,18,35}$ Brussee et al. found a good outcome in only $31 \%$ of their patient cohort following X-Stop implantation.? Tuschel et al. reported a $30 \%$ rate of revision surgery, mostly within the first year of implantation, due to failure of the device to adequately address the symptoms of stenosis. ${ }^{35}$ Kim et al. reported a $29 \%$ rate of spinous process fracture following interspinous spacer implantation. ${ }^{18}$ Bowers et al. found complications in $38 \%$ of X-Stop cases, and performed revision surgery in an alarming $85 \%$ of the patients in their series. ${ }^{6}$ Because of these concerns, intraspinous spacers have not replaced open lumbar decompression as the predominant method of treatment for LSS at the present time.

In the current study we found a substantial increase in the mean cross-sectional area of the spinal canal following the PLO procedure. Yamazaki et al. found that dural expansion following a lumbar decompression for LSS had a significant positive effect on positive clinical outcome. ${ }^{38}$ Siddiqui et al. reported a $21 \%$ increase in the cross-sectional area of the spinal canal in patients in the standing position following implantation of the X-Stop device, which is probably the mechanism for the observed clinical benefits. ${ }^{27}$ In the current study, we found a mean increase in the cross-sectional area of the spinal canal of $115 \%$. We hypothesize that the expansion in the cross-sectional area of the spinal canal and the associated decrease in pressure on the neural elements is the primary mechanism responsible for the positive clinical benefits observed in this study.

The SPORT study enrolled patients with LSS with and without spondylolisthesis who received either the usual nonoperative care, or surgery consisting of a decompressive lumbar laminectomy (or a decompressive laminectomy and fusion procedure for the population with spondylolisthesis) ${ }^{36,37}$ In the cohort without spondylolisthesis, the as-treated analysis demonstrated a mean improvement of $21.4 \pm 1.0$ points at the 1-year time point, compared with a mean baseline ODI score of $43.2 \pm 0.6$. This difference was statistically superior to the improvement of $8.9 \pm 1.1$ points observed in the nonoperative cohort. In contrast, the current study found a mean improvement of more than 29.7 points on the ODI scale at the 2 -year time point and a mean improvement of more than 33.6 points at the 5-year time point. Complication rates between the two studies were also quite different. In the SPORT stenosis cohort, transfusions were required in 10\% intraoperatively and in 5\% postoperatively, and dural tears were encountered in $9 \%$. In contrast, no transfusion or dural tears were encountered during the current PLO trial. The difference is probably due to the more invasive nature of open lumbar decompression surgery. In the SPORT spondylolisthesis cohort, even higher complication rates were observed, including transfusions in 35\% intraoperatively and in $16 \%$ postoperatively, dural tears in $12 \%$, wound infection in 5\%, and additional surgery within 12 months in $8 \%$. Longer-term follow-up of the SPORT study cohorts demonstrated a deterioration of the surgical benefits over time. In the 8-year follow-up report, the authors stated, "In the as-treated analyses of the randomized group, the advantage for surgery seen at 4 years diminished over time to the point that there were no longer any discernible differences between the treatment groups after 5 years." 20

The PLO procedure provides a novel surgical strategy for enlarging the spinal canal and neural foramen while using a minimally invasive approach. The theoretical advantages of this procedure include the lack of removal of normal anatomical structures and the reduced risk of major bleeding, infection, and medical complications compared with a traditional open lumbar decompression. Perineural scarring is also theoretically minimized due to the lack of neural manipulation. Postoperative instability is expected to be less likely because normal ligamentous structures are spared during the percutaneous PLO procedure, unlike laminectomy, which is known to reduce spinal stability. ${ }^{19,30}$ Following bone healing of the osteotomy site, the spinal canal is permanently enlarged, although the arthritic process may still progress in the future. The PLO procedure may be especially well suited for patients with significant medical comorbidities who are poor candidates for open surgery. A drawback of the current technique is the need for substantial intraoperative fluoroscopy, leading to radiation exposure for the patient and operative team. Strategies to limit intraoperative fluoroscopy usage through improvements in the procedural workflow and the use of computer-assisted image guidance have been undertaken since the current study to reduce fluoroscopy usage. Another clinical issue involves revision surgery at the levels of the pedicle osteotomy. Fortunately this is not difficult, because the pedicle-lengthening implant is simply threaded out of the pedicle passage and a pedicle screw that is size-appropriate for the pedicle passage is inserted. The 
manufacturer of the pedicle-lengthening device is able to provide pedicle screws with a size and shape that are optimal for revision of a pedicle-lengthening device passage.

Limitations of the current study should be acknowledged. First, this study included a relatively small number of patients and did not incorporate a control group due to the design of this pilot study. In the future, a large, prospective trial incorporating a control group is needed to confirm the findings of the present study and to better define the role of the PLO procedure for the treatment of spinal stenosis. Also, although 5-year follow-up is helpful, even longer-term follow-up will be required to define the durability of the treatment option. It must also be acknowledged that because the PLO procedure presents a new technique, a learning curve is anticipated that will require additional evaluation in the future. It should be noted that the current study includes the initial operations performed by the clinical investigator, and thus incorporates the effects of the investigator's learning curve with this procedure.

\section{Conclusions}

The PLO procedure provided substantial clinical improvements for patients with symptomatic LSS, with or without a grade I degenerative spondylolisthesis in this pilot study. The positive results were maintained over the 5-year follow-up time frame of the study. Given the prevalence of LSS in the elderly population, this approach deserves further clinical investigation in a large, randomized clinical trial.

\section{References}

1. Amundsen T, Weber H, Lilleås F, Nordal HJ, Abdelnoor M, Magnaes B: Lumbar spinal stenosis. Clinical and radiologic features. Spine (Phila Pa 1976) 20:1178-1186, 1995

2. Amundsen T, Weber H, Nordal HJ, Magnaes B, Abdelnoor M, Lilleâs F: Lumbar spinal stenosis: conservative or surgical management?: a prospective 10-year study. Spine (Phila Pa 1976) 25:1424-1436, 2000

3. Arnoldi CC, Brodsky AE, Cauchoix J, Crock HV, Dommisse GF, Edgar MA, et al: Lumbar spinal stenosis and nerve root entrapment syndromes. Definition and classification. Clin Orthop Relat Res (115):4-5, 1976

4. Asgarzadie F, Khoo LT: Minimally invasive operative management for lumbar spinal stenosis: overview of early and long-term outcomes. Orthop Clin North Am 38:387-399, vi-vii, 2007

5. Atlas SJ, Keller RB, Wu YA, Deyo RA, Singer DE: Longterm outcomes of surgical and nonsurgical management of lumbar spinal stenosis: 8 to 10 year results from the Maine Lumbar Spine Study. Spine (Phila Pa 1976) 30:936-943, 2005

6. Bowers C, Amini A, Dailey AT, Schmidt MH: Dynamic interspinous process stabilization: review of complications associated with the X-Stop device. Neurosurg Focus 28(6):E8, 2010

7. Brussee P, Hauth J, Donk RD, Verbeek AL, Bartels RH: Self-rated evaluation of outcome of the implantation of interspinous process distraction (X-Stop) for neurogenic claudication. Eur Spine J 17:200-203, 2008

8. Burdock EI, Fleiss JL, Hardesty AS: A new view of interobserver agreement. Personnel Psychol 16:373-484, 1963

9. Deyo RA, Mirza SK, Martin BI, Kreuter W, Goodman DC, Jarvik JG: Trends, major medical complications, and charges associated with surgery for lumbar spinal stenosis in older adults. JAMA 303:1259-1265, 2010

10. ECRI Health Technology Assessment Group: Evidence Report/Technology Assessment Number 32: Treatment of Degenerative Lumbar Spinal Stenosis. Rockville, MD: AHRQ, 2001 (http:// www.spinalstenosis.org/AHRQ\%20 $\mathrm{WEB} /$ mainpage.htm) [Accessed January 15, 2018]

11. Fredman B, Arinzon Z, Zohar E, Shabat S, Jedeikin R, Fidelman ZG, et al: Observations on the safety and efficacy of surgical decompression for lumbar spinal stenosis in geriatric patients. Eur Spine J 11:571-574, 2002

12. Fu KM, Smith JS, Polly DW Jr, Perra JH, Sansur CA, Berven $\mathrm{SH}$, et al: Morbidity and mortality in the surgical treatment of 10,329 adults with degenerative lumbar stenosis. J Neurosurg Spine 12:443-446, 2010

13. Hamasaki T, Tanaka N, Kim J, Okada M, Ochi M, Hutton WC: Biomechanical assessment of minimally invasive decompression for lumbar spinal canal stenosis: a cadaver study. J Spinal Disord Tech 22:486-491, 2009

14. Jansson KA, Blomqvist P, Granath F, Németh G: Spinal stenosis surgery in Sweden 1987-1999. Eur Spine J 12:535541,2003

15. Jansson KA, Németh G, Granath F, Blomqvist P: Spinal stenosis re-operation rate in Sweden is $11 \%$ at 10 years-a national analysis of 9,664 operations. Eur Spine J 14:659-663, 2005

16. Katz JN, Lipson SJ, Brick GW, Grobler LJ, Weinstein JN, Fossel AH, et al: Clinical correlates of patient satisfaction after laminectomy for degenerative lumbar spinal stenosis. Spine (Phila Pa 1976) 20:1155-1160, 1995

17. Katz JN, Lipson SJ, Chang LC, Levine SA, Fossel AH, Liang $\mathrm{MH}$ : Seven- to 10-year outcome of decompressive surgery for degenerative lumbar spinal stenosis. Spine (Phila Pa 1976) 21:92-98, 1996

18. Kim DH, Tantorski M, Shaw J, Martha J, Li L, Shanti N, et al: Occult spinous process fractures associated with interspinous process spacers. Spine (Phila Pa 1976) 36:E1080E1085, 2011

19. Lee MJ, Bransford RJ, Bellabarba C, Chapman JR, Cohen AM, Harrington RM, et al: The effect of bilateral laminotomy versus laminectomy on the motion and stiffness of the human lumbar spine: a biomechanical comparison. Spine (Phila Pa 1976) 35:1789-1793, 2010

20. Lurie JD, Tosteson TD, Tosteson A, Abdu WA, Zhao W, Morgan TS, et al: Long-term outcomes of lumbar spinal stenosis: eight-year results of the Spine Patient Outcomes Research Trial (SPORT). Spine (Phila Pa 1976) 40:63-76, 2015

21. Mannion RJ, Guilfoyle MR, Efendy J, Nowitzke AM, Laing RJ, Wood MJ: Minimally invasive lumbar decompression: long-term outcome, morbidity, and the learning curve from the first 50 cases. J Spinal Disord Tech 25:47-51, 2012

22. Mlyavykh S, Ludwig SC, Mobasser JP, Kepler CK, Anderson DG: Twelve-month results of a clinical pilot study utilizing pedicle-lengthening osteotomy for the treatment of lumbar spinal stenosis. J Neurosurg Spine 18:347-355, 2013

23. Podichetty VK, Spears J, Isaacs RE, Booher J, Biscup RS: Complications associated with minimally invasive decompression for lumbar spinal stenosis. J Spinal Disord Tech 19:161-166, 2006

24. Pratt RK, Fairbank JC, Virr A: The reliability of the Shuttle Walking Test, the Swiss Spinal Stenosis Questionnaire, the Oxford Spinal Stenosis Score, and the Oswestry Disability Index in the assessment of patients with lumbar spinal stenosis. Spine (Phila Pa 1976) 27:84-91, 2002

25. Rahimi-Movaghar V, Rasouli MR, Vaccaro AR: Patient outcomes vs a minimally invasive approach in lumbar spinal stenosis: which is more important? Neurosurgery 67:E1180, 2010

26. Rosen DS, O’Toole JE, Eichholz KM, Hrubes M, Huo D, 
Sandhu FA, et al: Minimally invasive lumbar spinal decompression in the elderly: outcomes of 50 patients aged 75 years and older. Neurosurgery 60:503-510, 2007

27. Siddiqui M, Karadimas E, Nicol M, Smith FW, Wardlaw D: Influence of X Stop on neural foramina and spinal canal area in spinal stenosis. Spine (Phila Pa 1976) 31:2958-2962, 2006

28. Stucki G, Daltroy L, Liang MH, Lipson SJ, Fossel AH, Katz JN: Measurement properties of a self-administered outcome measure in lumbar spinal stenosis. Spine (Phila Pa 1976) 21:796-803, 1996

29. Stucki G, Liang MH, Fossel AH, Katz JN: Relative responsiveness of condition-specific and generic health status measures in degenerative lumbar spinal stenosis. J Clin Epidemiol 48:1369-1378, 1995

30. Tai CL, Hsieh PH, Chen WP, Chen LH, Chen WJ, Lai PL: Biomechanical comparison of lumbar spine instability between laminectomy and bilateral laminotomy for spinal stenosis syndrome - an experimental study in porcine model. BMC Musculoskelet Disord 9:84, 2008

31. Toyone T, Tanaka T, Kato D, Kaneyama R, Otsuka M: Patients' expectations and satisfaction in lumbar spine surgery. Spine (Phila Pa 1976) 30:2689-2694, 2005

32. Truumees E: Spinal stenosis: pathophysiology, clinical and radiologic classification. Instr Course Lect 54:287-302, 2005

33. Tuli SK, Yerby SA, Katz JN: Methodological approaches to developing criteria for improvement in lumbar spinal stenosis surgery. Spine (Phila Pa 1976) 31:1276-1280, 2006

34. Turner JA, Ersek M, Herron L, Deyo R: Surgery for lumbar spinal stenosis. Attempted meta-analysis of the literature. Spine (Phila Pa 1976) 17:1-8, 1992

35. Tuschel A, Chavanne A, Eder C, Meissl M, Becker P, Ogon M: Implant survival analysis and failure modes of the XStop interspinous distraction device. Spine (Phila Pa 1976) 38:1826-1831, 2013

36. Weinstein JN, Lurie JD, Tosteson TD, Zhao W, Blood EA, Tosteson ANA, et al: Surgical compared with nonoperative treatment for lumbar degenerative spondylolisthesis. Fouryear results in the Spine Patient Outcomes Research Trial (SPORT) randomized and observational cohorts. J Bone Joint Surg Am 91:1295-1304, 2009

37. Weinstein JN, Tosteson TD, Lurie JD, Tosteson A, Blood E, Herkowitz H, et al: Surgical versus nonoperative treatment for lumbar spinal stenosis four-year results of the Spine Patient Outcomes Research Trial. Spine (Phila Pa 1976) 35:1329-1338, 2010

38. Yamazaki K, Yoshida S, Ito T, Toba T, Kato S, Shimamura T: Postoperative outcome of lumbar spinal canal stenosis after fenestration: correlation with changes in intradural and extradural tube on magnetic resonance imaging. J Orthop Surg (Hong Kong) 10:136-143, 2002

39. Yoshimoto M, Takebayashi T, Kawaguchi S, Tsuda H, Ida K, Wada T, et al: Minimally invasive technique for decompression of lumbar foraminal stenosis using a spinal microendoscope: technical note. Minim Invasive Neurosurg 54:142146,2011

40. Zucherman JF, Hsu KY, Hartjen CA, Mehalic TF, Implicito DA, Martin MJ, et al: A multicenter, prospective, randomized trial evaluating the X STOP interspinous process decompression system for the treatment of neurogenic intermittent claudication: two-year follow-up results. Spine (Phila Pa 1976) 30:1351-1358, 2005

41. Zucherman JF, Hsu KY, Hartjen CA, Mehalic TF, Implicito DA, Martin MJ, et al: A prospective randomized multi-center study for the treatment of lumbar spinal stenosis with the X STOP interspinous implant: 1-year results. Eur Spine J 13:22-31, 2004

\section{Disclosures}

Drs. Anderson and Ludwig report an ownership stake in Innovative Surgical Designs, Inc. (ISD), which manufactures the device that was the subject of this study. However, neither had a role in the data collection or data analysis for this study. Dr. Anderson is also a consultant for DePuy Synthes and K2M. Dr. Ludwig is also a consultant for DePuy Synthes, K2M, and Globus Medical. He has direct stock ownership in ASIP, and is a patent holder with DePuy Synthes and Globus Medical. The study was supported in part by a research grant from ISD to the Research Department of the Research Institute of Traumatology and Orthopaedics, Nizhniy Novgorod, Russia.

\section{Author Contributions}

Conception and design: Anderson, Mlyavykh. Acquisition of data: Mlyavykh. Analysis and interpretation of data: Mlyavykh, Kepler. Drafting the article: all authors. Critically revising the article: all authors. Reviewed submitted version of manuscript: all authors. Approved the final version of the manuscript on behalf of all authors: Anderson. Statistical analysis: Kepler. Administrative/ technical/material support: Mlyavykh. Study supervision: Mlyavykh.

\section{Correspondence}

D. Greg Anderson: Thomas Jefferson University/Rothman Institute, Philadelphia, PA. greg.anderson@rothmaninstitute.com. 